\title{
A Comparison of the Effects of Solar Radiation on Sandy-Loam and Clay-Loam Soils with Convective Boundary Condition
}

\author{
Folake Oyedigba Akinpelu ${ }^{1,2}$, Olalekan Ayodeji Olaleye ${ }^{* 3}$, Raimi Marcus Alabison ${ }^{3}$ \\ ${ }^{1}$ Department of Pure and Applied Mathematics, Ladoke Akintola University of Technology, Oyo, Nigeria \\ ${ }^{2}$ Department of Mathematics, University of Lagos, Akoka, Yaba, Lagos, Nigeria \\ ${ }^{3}$ Department of Statistics, The Federal Polytechnic, Ede, Osun State, Nigeria \\ * Corresponding author email: hezekiaholaleye@gmail.com
}

Received: 27 September 2019 / Revised: 16 October 2019 / Accepted: 01 November 2019 / Published: 04 November 2019

\begin{abstract}
A comparison of the effects of solar radiation on sandy-loam and clay-loam soils with convective boundary condition was made. The dimensional governing equations (the continuity, momentum and energy equations) were converted to non-dimensional form using some set of dimensionless quantities, which resulted to a pair of partial differential equations of second order. With the use of perturbation method, these equations were reduced to ordinary differential equation and then solved analytically. Using the numerical values of the thermal conductivities of sandy-loam and clay-loam soils, a good comparison was made between the effects of the solar radiation parameter and internal heat generation parameter on the two soil samples. These results were worked out with the use of Matlab R2009b and visibly displayed on graphs for clearer illustration. For a rise in the intensity of solar radiation and mounting internal heat, the temperature of the soils increased generally. However, the proportion of moisture content influenced the level and the rate at which the temperature is boosted in both soil samples.
\end{abstract}

Keywords: Clay-loam soil, internal heat, perturbation method, Prandtl number, sandy-loam soil, solar radiation

\section{Introduction}

Information about soil temperature is very essential and required in the vast area of Agriculture, soil science and engineering. Some crops thrive under a relatively good soil temperature while some require lower temperature to germinate and grow. The thermal properties of these various soils can serve as a pointer to what is likely going to be their response to different sources of temperature. Though there are other sources of heat, like the internal heat which comes from the decay of naturally radioactive isotopes emanating from the earth crust, yet the main source of heat available for soils is solar. This is when the sun emits some electromagnetic waves towards the earth surface out of which a good portion is been absorbed by the soil. Moreover, because of the nature of these individual soils, it may be necessary to combine two or more soil types in order to get the best of what the farmer is looking for before planting. In the light of this, researchers have over time been examined the thermal properties of various soils. Amrollah [1] for example studied the thermal properties of clay-loam soil which is the major agricultural soil in Arak, Iran. His results revealed that the moisture content and the bulk density have significant influence on the thermal conductivity of the soil sample. However, the bulk density increases the thermal properties of the soil more than the moisture content. AbuHamdeh and Reeder [2] investigated the effects of density, moisture, salt concentration and organic matter on the soil thermal conductivity. Their work shows that at soil densities that ranges from $1230 \mathrm{~kg} / \mathrm{m}^{3}$ to $1590 \mathrm{~kg} / \mathrm{m}^{3}$ and moisture contents that ranges from $1.4 \%$ to $21.2 \%$, the thermal conductivity of sand increased from $0.58 \mathrm{~W} / \mathrm{m} \mathrm{K}$ to $1.94 \mathrm{~W} / \mathrm{m} \mathrm{K}$, that of loam 
increased from $0.29 \mathrm{~W} / \mathrm{m} \mathrm{K}$ to $0.76 \mathrm{~W} / \mathrm{m} \mathrm{K}$, the one of clay-loam increased from $0.36 \mathrm{~W} / \mathrm{m} \mathrm{K}$ to $0.69 \mathrm{~W} / \mathrm{m} \mathrm{K}$, and that of sandy-loam increased from $0.19 \mathrm{~W} / \mathrm{m} \mathrm{K}$ to $1.12 \mathrm{~W} / \mathrm{m} \mathrm{K}$. Under a frozen and uunfrozen conditions, Ying and Bingcheng [3] examined the peat soil and sandy soil thermal properties. They used a method of dual-probe heat-pulse (DPHP) to measure thermal properties of six peat soils collected from an oil mine sand reclamation study site. Generally, they discovered that the peat soil decreased the thermal conductivity when it is been compared with the sandy soil. When the water content increases, their result thermal shows that the thermal conductivity also increases but there was decrease in the heat capacity.

Sen et al [4] examined a relationship between the matric suction and the thermal conductivity of soils generally. Using eighteen different soil samples, their results established that universally when the soils are dry, irrespective of the value of the bulk densities and the soil texture, there is a relationship between the thermal conductivity and the matric suction. But at wet soils, the bulk density and the texture greatly affect the relationship between the thermal conductivity and the matric suction by making it vastly nonlinear. Ian et al [5] formulated a model to examine in the soils the heat transfer process. The model incorporated the moisture level, the temperature and the density of the soil sample. The model also makes a room for estimating the thermal conductivity with laboratory experiments. David et al [6] compared thermal conductivities of soils with various grain classes and sizes related to their depth using direct measurement and calculated methods. Their results showed that when the soil is saturated, the thermal conductivity increases with increase in the quantity of quartz or sand grains and bulk density. Moreover, in calculating the thermal conductivity, regular bulk density gives the best fit for the formula.

Peter et al. [7] in their research established the fact that properties of soil are been altered by thermal remediation. They pointed out that though the use of the thermal remedial method has the ability to treat contaminated soils without waiting for a long period of time, yet the method poses some threats of reducing the functional capacity of the soil in terms of minerals, texture, organic matter, $\mathrm{pH}$, heavy metals and sustainability of the vegetation by the soil, which are all based on the temperature used in the heating and the time of the heating.

Xuezhen et al. [8] developed and integrated an irrigation method into a model of Weather Research and Forecasting alongside the NoahMP land surface scheme to examine the irrigation effects on surface climate. Their research was done in Northwest China, at the River Basin of Heihe where the water that comes from this mountainous location is mainly used to irrigate their farmland. They observed that as a result of the irrigation, the daily mean temperature in the area where the irrigation was done reduced by approximately $1.7^{\circ} \mathrm{C}$, while the humidity was raised by approximately $2.3 \mathrm{~g} \mathrm{~kg}^{-1}$. Some others include Momen et al [9] who applied this in the study of under Crack-Sealed Asphat pavements in order to understand the damage done by moisture content from the underground soil and to give proper guides while building crack seals to reduce the amount of moisture that may be entrapped under these pavements. Onwuka [10] examined crop growth as been influenced by soil temperature and some other properties. Oladunjoye and Sanuade [11] studied the thermal diffusivity and specific heat of soils in Olorunsogo Power plant in south-west Nigeria. Danelichen et al [12] used different methods in the Brazilian Pantanal to estimate thermal diffusivity of a gleyic solonetz soil. Monika [13] worked on selected soil thermal conductivity models. Usowicz and Usowicz [14] compared results of experimental and estimation methods of determining thermal conductivity of soils. Ross [15] researched into the precipitation, the temperature and the sunlight effects on the soil gardens for correct plantation. Smriti [16] studied some six conditions that are suitable for rice cultivation. Kamal et al [17] researched into understanding the Earth air tunnel heat exchanger performance as a factor of some soil properties and the geometrical flow. Under an inorganic and organic fertilization, Ahmed et al 
[18] studied organic nitrogen and organic carbon mineralization in semi-arid soils.

As stated above, one main importance of knowing the thermal properties of these soils is to be able to predict their reaction to temperature from a source. Therefore, this work compares the effects of solar radiation on sandy-loam and clayloam soils while imposing a convective boundary condition.

\section{Mathematical Analysis}

The heat transfer equation in two-dimensional form and in unsteady state is considered. The flow is reduced to a function of vertical axis ( $\left.z^{\prime}-a x i s\right)$ and time $\left(t^{\prime}\right)$ only following Mohammed [19] by assuming an infinite flow along the horizontal axis $\left(y^{\prime}-\right.$ axis $)$. The solar radiation is taken to be in the direction along gravity toward the soil directly which is an optically thin environment. With convective boundary condition of sine of function and under the Boussinesq's approximation, the governing equations are written as below:

Continuity equation

$$
\frac{\partial \bar{w}}{\partial \bar{z}}=0
$$

Energy equation

$$
\frac{\partial \bar{T}}{\partial \bar{t}}+\bar{w} \frac{\partial \bar{T}}{\partial \bar{z}}=\frac{k}{\rho C_{p}} \frac{\partial^{2} \bar{T}}{\partial \bar{z}^{2}}-\frac{1}{\rho C_{p}} \frac{\partial \bar{q}_{r}}{\partial \bar{z}}+\frac{1}{\rho C_{p}} Q_{0}\left(\bar{T}-\bar{T}_{\infty}\right)
$$

Subject to the following boundary conditions:

$$
\bar{T}(0, t)=\bar{T}_{\infty}+\left(\bar{T}_{w}-\bar{T}_{\infty}\right)\left[1+A \sin \left(\frac{\pi \bar{t}}{L}\right)\right]
$$

(i.e. at the soil/ground surface)

$$
\bar{T}(\infty, t) \rightarrow \bar{T}_{\infty}
$$

(i.e. when the soil depth increases indefinitely) where, $\bar{z}$ is the dimensional soil depth perpendicular to $\bar{y} . \bar{t}$ and $\bar{w}$ are the dimensional time and suction velocity respectively. $\bar{T}, \bar{T}_{w}$ and $\bar{T}_{\infty}$ are the dimensional temperature, wall temperature and free stream temperature respectively. $\rho, C_{p}, k$ and $\bar{q}_{r}$ are density, specific heat capacity, thermal conductivity and the Radiative heat flux respectively.
Introducing the following dimensionless parameters:

$$
\begin{aligned}
& w=\frac{\bar{t} w_{0}^{2}}{t}, \quad z=\frac{w_{0} \bar{z}}{w}, \quad \theta=\frac{\bar{T}-\bar{T}_{\infty}}{\bar{T}_{w}-\bar{T}_{\infty}}, \\
& \omega=\frac{w \bar{\omega}}{w_{0}^{2}}, t=\frac{\bar{t}}{L}
\end{aligned}
$$

And the variable suction velocity as used by Nwaigwe [20] is given as

$$
\bar{w}=-w_{0}\left(1+\varepsilon \lambda e^{i \bar{\omega} \bar{t}}\right)
$$

where $w_{0}$ is the initial suction velocity, $\lambda$ is the suction parameter and $\omega$ is the frequency of oscillation. The negative sign indicates that the suction is towards the surface of the ground.

Moreover, $\lambda$ and $\varepsilon$ are very small such that $\varepsilon \lambda<<1$.

Besides, according to Krishna and Reddy [21] the radiative heat flux is given as

$$
\frac{\partial \bar{q}_{r}}{\partial \bar{z}}=4 \alpha^{2}\left(\bar{T}-\bar{T}_{\infty}\right)
$$

where $\alpha$ is the absorption coefficient.

Also, following the trend of Kareem and Salawu [22], Akinpelu et al [23] and Akinbobola and Okoya [24], the thermal conductivity is chosen to be linear function of time and given as:

$k=k_{\infty}(1+\xi t)$

where $\xi$, $t$ and $k_{\infty}$ are the variable thermal conductivity parameter, time and the constant thermal conductivity.

Substituting equations (5) - (8) into equation (2), we obtained,

$$
\frac{\partial \theta}{\partial t}-\left(1+\varepsilon A e^{i \omega t}\right) \frac{\partial \theta}{\partial z}=\frac{1}{P_{r}}\left\{\frac{\partial}{\partial z}\left((1+\xi t) \frac{\partial \theta}{\partial z}\right)\right\}-R^{2}+Q \theta
$$

The boundary conditions (3) - (4) with the dimensionless parameters (5) also became

$\theta(0, t)=1+A \sin (\pi t)$

(at the soil/ground surface)

$$
\theta(\infty, t) \rightarrow 0
$$

(when the soil depth increases indefinitely) where the Prandtl number is given as $P_{r}=\frac{w \rho C_{p}}{k_{\infty}}$, the radiation parameter is 
given as $R^{2}=\frac{4 \alpha^{2} \theta w}{w_{0}^{2}}$ and the internal heat generation parameter is given as $Q=\frac{Q_{0} w}{\rho C_{p} w_{0}^{2}}$.

\section{Method of Solution}

Equation (9) is a partial differential equation of second order which can be reduce to ordinary differential equation and solved analytically. In view of this, the regular perturbation method is employed and the assumed solution for the temperature gradient is given as:

$$
\theta(z, t)=\theta_{0}(z)+\varepsilon e^{i \omega t} \theta_{1}(z)
$$

Substituting equation (12) and its derivatives into (9), while neglecting the higher order terms $o(\varepsilon)^{2}$ and some more simplifications,

$\theta_{0}^{\prime \prime}+\xi t \theta_{0}^{\prime \prime}+P_{r} \theta_{0}^{\prime}+P_{r} Q \theta_{0}=P_{r} R^{2}$

$\theta_{1}^{\prime \prime}+\xi t \theta_{1}^{\prime \prime}+P_{r} \theta_{1}^{\prime}+P_{r} Q \theta_{1}-P_{r} i \omega \theta_{1}=-P_{r} A \theta_{0}$

The primes correspond to ordinary differentiation with respect to variable $z$.

Employing equation (12) also, the corresponding boundary conditions (10) and (11) become:

$\theta_{0}=1+A \sin (\pi t), \quad \theta_{1}=0$

(at soil/ground surface)

$\theta_{0} \rightarrow 0, \quad \theta_{1} \rightarrow 0$

(when the soil depth increases indefinitely)

Solving equations (13) - (14) analytically using auxiliary equation and undetermined coefficients methods alongside the boundary conditions (15) - (16), the resulted transient temperature distribution for the soil is gotten to be:

$$
\theta=N_{1}+N_{2}
$$

where,

$$
\begin{aligned}
& N_{1}=C_{1} e^{m_{1} z}+C_{2} e^{m_{2} z}+C_{3} \\
& N_{2}=\varepsilon e^{i \omega t}\left(C_{4} e^{m_{3} z}+C_{5} e^{m_{4} z}+C_{6} e^{m_{1} z}+C_{7} e^{m_{2} z}\right) \\
& m_{1}=-\frac{P_{r}}{2(1+\xi t)}+\sqrt{\frac{P_{r}^{2}}{4(1+\xi t)^{2}}-\frac{P_{r} Q}{1+\xi t}} \\
& m_{2}=-\left(\frac{P_{r}}{2(1+\xi t)}+\sqrt{\frac{P_{r}^{2}}{4(1+\xi t)^{2}}-\frac{P_{r} Q}{1+\xi t}}\right)
\end{aligned}
$$

$$
m_{3}=-\frac{P_{r}}{2(1+\xi t)}+\sqrt{\frac{P_{r}^{2}}{4(1+\xi t)^{2}}+\frac{P_{r}(i \omega-Q)}{1+\xi t}}
$$

$$
m_{4}=-\left(\frac{P_{r}}{2(1+\xi t)}+\sqrt{\frac{P_{r}^{2}}{4(1+\xi t)^{2}}+\frac{P_{r}(i \omega-Q)}{1+\xi t}}\right)
$$

$C_{1}=-C_{3} e^{-m_{1} z}$

$C_{2}=1+A \sin (\pi t)+C_{3}\left(e^{-m_{1} z}-1\right)$

$C_{3}=R^{2} / Q$

$C_{4}=\frac{-C_{6} e^{m_{1} z}}{e^{m_{3} z}}$

$C_{5}=-\left(C_{4}+C_{6}+C_{7}\right)$

$$
C_{6}=\frac{-P_{r} A m_{1} C_{1}}{m_{1}^{2}+s t m_{1}^{2}+P_{r} m_{1}+P_{r} Q-P_{r} i \omega}
$$

$C_{7}=\frac{-P_{r} A m_{2} C_{2}}{m_{2}^{2}+s t m_{2}^{2}+P_{r} m_{2}+P_{r} Q-P_{r} i \omega}$

\section{Results and Discussion}

The numerical results of equation (17) which is the model developed for transient temperature of the soils was computed using Matlab R2009b software and displayed on graphs. Effects of the emerged physical parameters which are the solar radiation parameter and the internal heat generation parameter $(\mathrm{Q})$ were examined on the temperature of sandy-loam and clay-loam soils, and a good comparison was made. Furthermore, the Prandtl number $(\mathrm{Pr})$ was also examine on the temperature gradient of both soil samples.

In the table 1 below, values of the thermal conductivities and moisture content used for both soil samples are shown.

Table 1: Thermal conductivities and moisture content for sandy-loam and clay-loam soils [2]

\begin{tabular}{|l|l|l|}
\hline Soil type & $\begin{array}{l}\text { Thermal } \\
\text { Conductivity } \\
\text { (W/m K) }\end{array}$ & $\begin{array}{l}\text { Moisture } \\
\text { Content (\%) }\end{array}$ \\
\hline Sandy-loam & 0.19 to 1.12 & 1.4 to 21.2 \\
\hline Clay-loam & 0.36 to 0.69 & 1.4 to 21.2 \\
\hline
\end{tabular}

In addition, some default values for some of the parameters involved were adopted in the study except or otherwise stated. These include the 
Akinpelu et al., Int. Ann. Sci.; Vol. 8, Issue 1, pp: 130-137, 2020

Prandtl number $P_{r}=0.71$, internal heat generation $Q=0.01$, frequency of oscillation $\omega=\frac{\pi}{2}, \quad$ epsilon $\varepsilon=0.01, \quad$ time $t=1.0$, suction parameter $\lambda=0.5$, radiation parameter $R=0.1$ and the amplitude of oscillation $A=1$ In figure 1 , as the thermal conductivities of both soil samples (the sandy-loam and clay-loam) increased as a result of increase in the moiture content from $1.4 \%$ to $21.2 \%$ wet basis, the corrensponding temperature of these soils increased as well. However, the rate of increase in the sandy-loam is more than that of the clayloam.

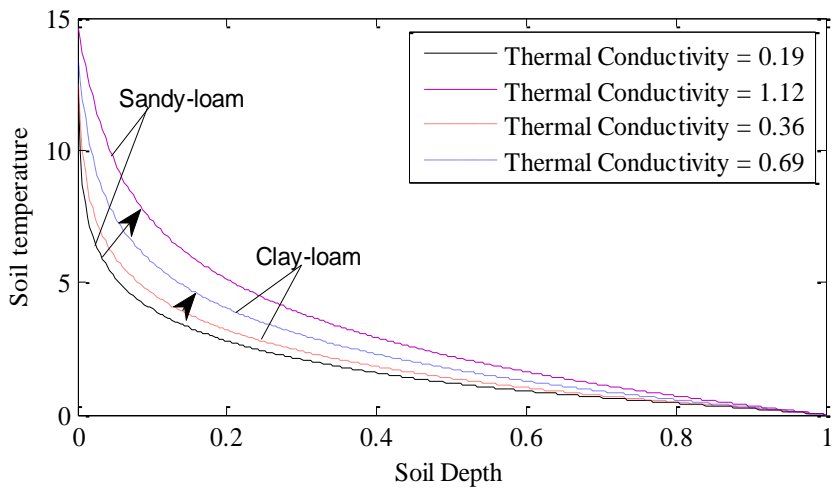

Figure 1: Temperature profile for increasing thermal conductivity of both the sandy-loam and clay-loam soils at about $1.4 \%$ and $21.2 \%$ moiture content.

Figures 2, and 3 depict the temperature profiles at increasing radiation parameter and internal heat generation parameter respectively for sandyloam soil, at $1.4 \%$ moisture content or wet basis. The results show that as both parameters increased, the temperature of the soil generally increased as well.

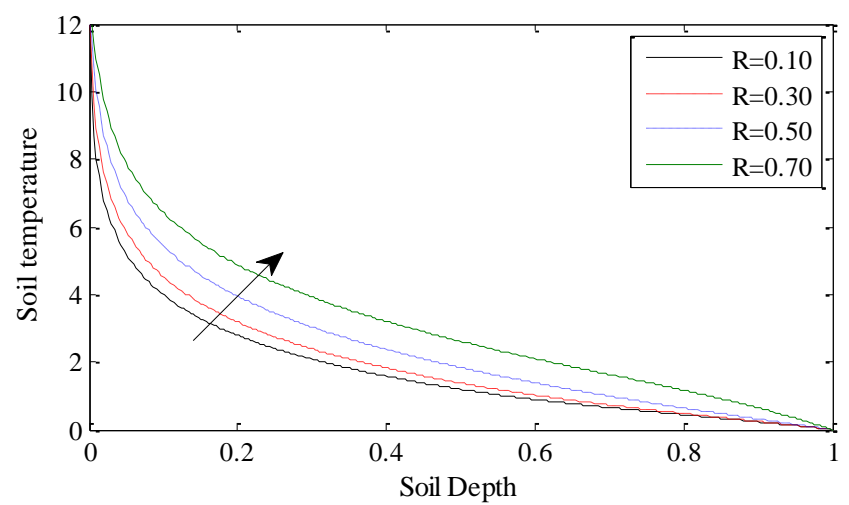

Figure 2: Temperature profile for increasing radiation parameter on sandy-loam soil at about $1.4 \%$ moiture content.

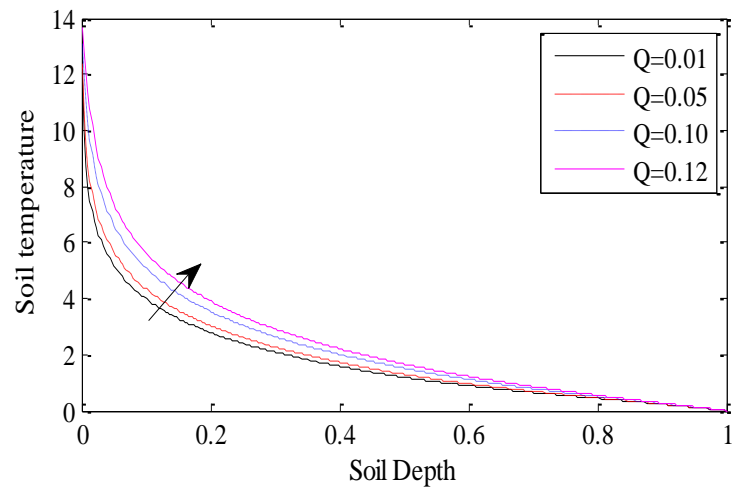

Figure 3: Temperature profile for increasing internal heat generation parameter on sandy-loam soil at about $1.4 \%$ moiture content.

This is similar to what happened in figures 5 and 6 which are the temperature profiles for increasing values of solar radiation and internal heat generation parameters respectively for the clay-loam soil, at the same $1.4 \%$ level of moisture content or wet basis. It is evidently seen that the temperature of the soil also increased. Figures 4 and 7 represent temperature profiles for different values of Prandtl number for both the sandyloam and clay-loam soils respectively, also at $1.4 \%$ wet basis. As the Prandtl number increased, the temperature of both soil samples decreased.

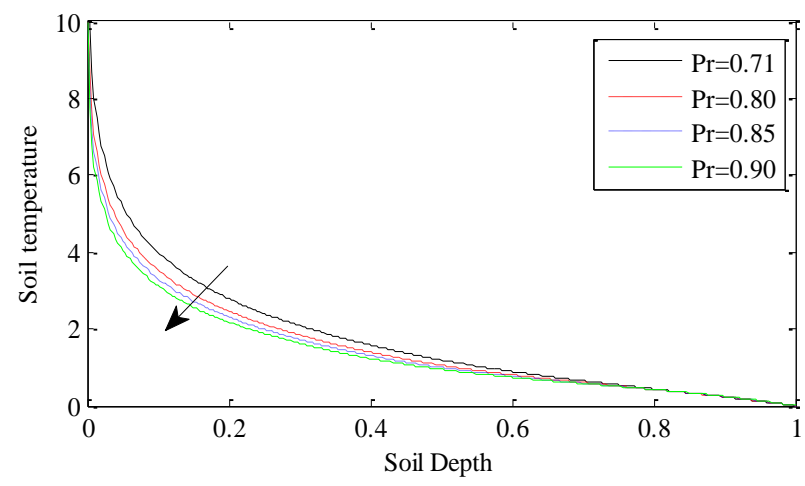

Figure 4: Temperature profile for increasing Prandtl number on sandy-loam soil at about $1.4 \%$ moiture content.

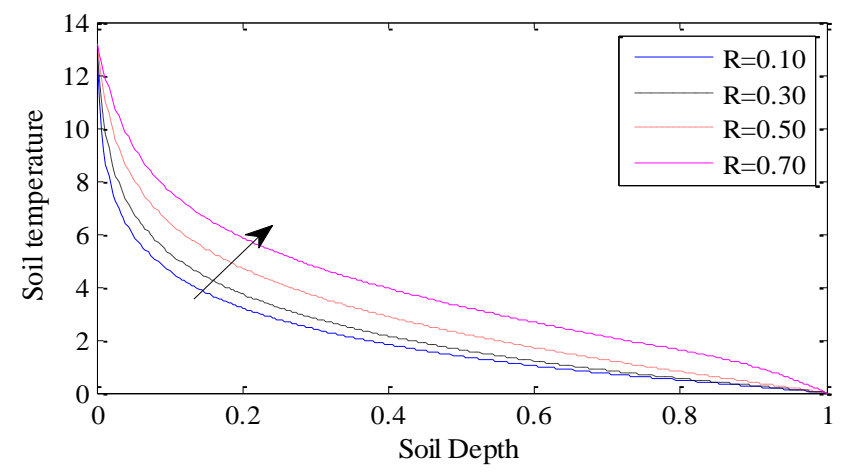

Figure 5: Temperature profile for increasing radiation parameter on clay-loam soil at about $1.4 \%$ moiture content. 


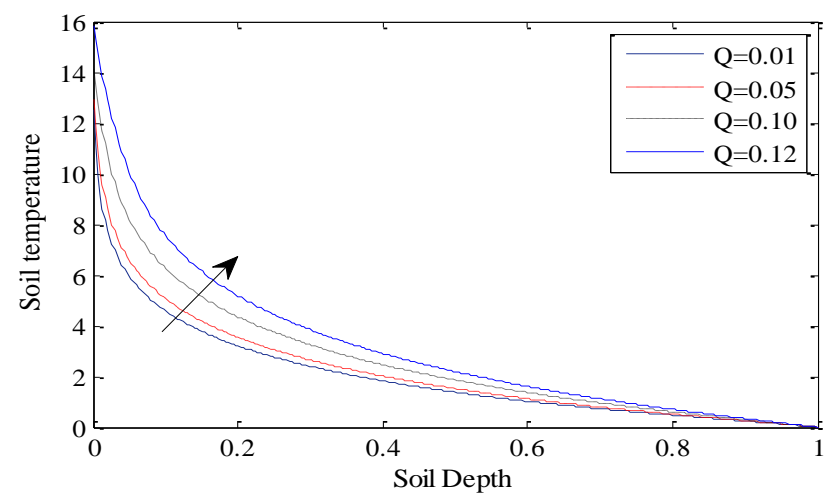

Figure 6: Temperature profile for increasing internal heat generation parameter on clay-loam soil at about $1.4 \%$ moiture content.

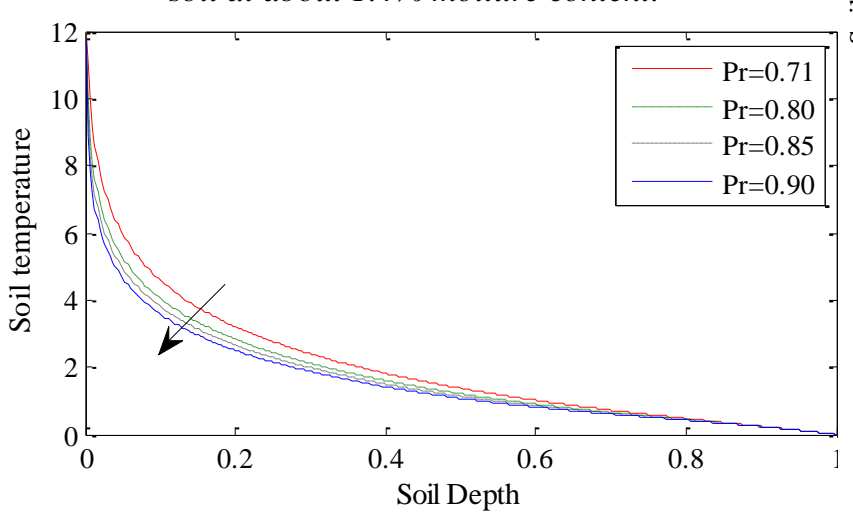

Figure 7: Temperature profile for increasing Prandtl number on clay-loam soil at about $1.4 \%$ moiture content.

Figure 8 is the temperature profile for the comparison of the effects of rising radiation parameter on sandy-loam and clay-loam soils. With the moisture content of about $1.4 \%$, as the intensity of the solar radiation increases, the level of increase in temperature of the clay-loam soil is more than that of the sandy-loam. Besides, the rate of the increase is also slightly greater in clayloam than in sandy-loam.

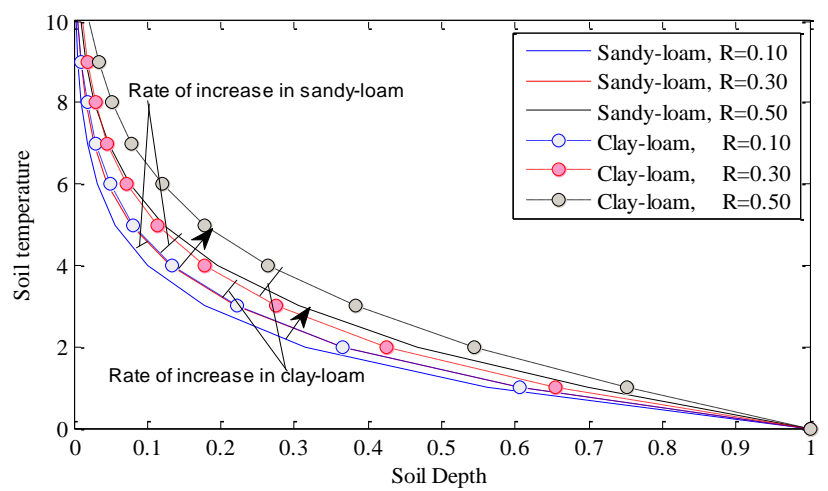

Figure 8: Temperature profile for the comparison of the effects of rising radiation parameter on sandyloam and clay-loam soils at about $1.4 \%$ wet level.
However, in figure 9, when the moisture content is increased to $21.2 \%$ wet level, at mounting solar radiation, then the level of increase of the temperature of the sandy-loam becomes greater than that of the clay-loam. Moreover, the rate of the increment in sandy-loam also becomes greater than that of the clay-loam.

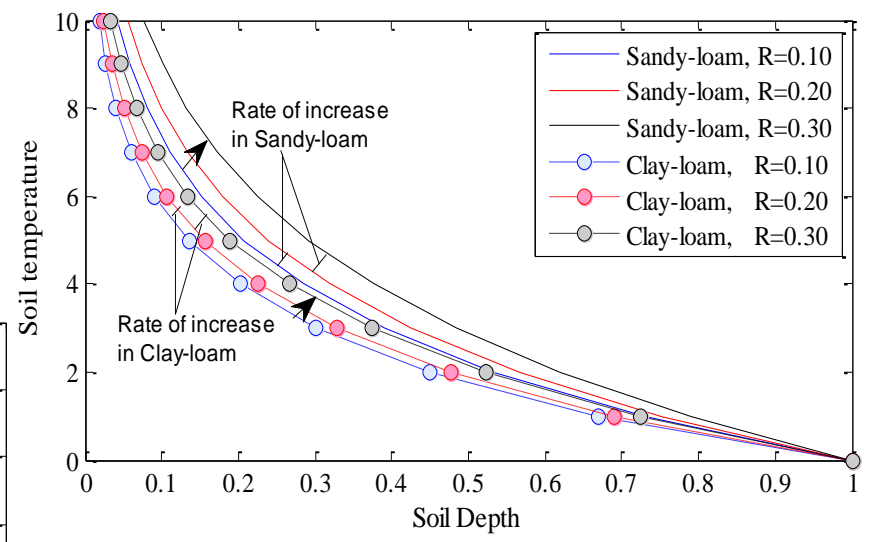

Figure 9: Temperature profile for the comparison of the effects of rising radiation parameter on sandyloam and clay-loam soils at about $21.2 \%$ wet level.

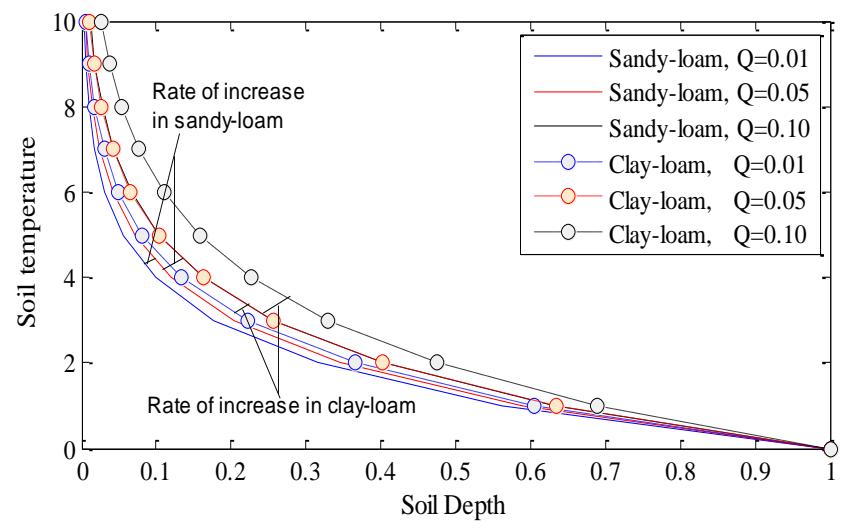

Figure 10: Temperature profile for the comparison of the effects of growing internal heat generation parameter on sandy-loam and clay-loam soils at about $1.4 \%$ wet level.

According to figure 10, which is the Temperature profile for the comparison of the effects of growing internal heat generation parameter on sandy-loam and clay-loam soils, at an increasing internal heat, with about $1.4 \%$ level of moisture content, the level of temperature rise in clay-loam soil is more than that of the sandy-loam. In addition, the rate of increase in this temperature difference is slightly more in clay-loam soil than in sandy loam. 


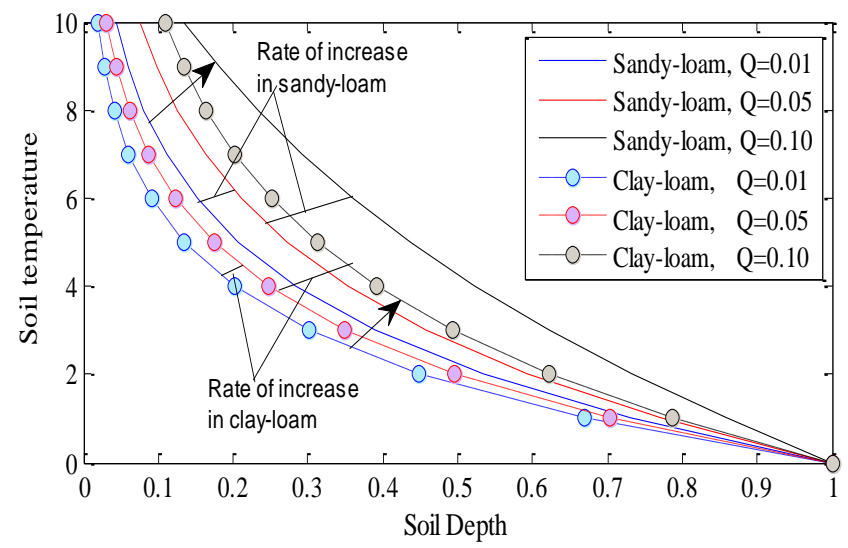

Figure 11: Temperature profile for the comparison of the effects of growing internal heat generation parameter on sandy-loam and clay-loam soils at about $21.2 \%$ wet level.

On the other hand, in figure 11, when the moisture content or the wet basis is increased to $21.2 \%$, the level of temperature rises in the sandyloam soil shot up more than that of the clay-loam. The rate of this increase is also slightly more in the sandy-loam soil than that of clay-loam.

\section{Conclusion}

A study on the comparison of the effects of solar radiation on sandy-loam and clay-loam soils with convective boundary condition was made. The work revealed that when the intensity of solar radiation is on the rise, the temperature of the soil samples, i.e. sandy-loam and clay-loam, increases generally. Similarly, a growing internal heat will also enhance the temperature of the soils in a general sense. Nonetheless, the level of moisture content or the wet basis determined the level and the rate at which the temperature is boosted in both soil samples. When the wet level or moisture content of the two soil samples are increased, then the rising solar radiation and internal heat amplify the temperature of the soils more than when their wet level is low. This is because water generally increases the thermal conductivity of the soil. Since most biological processes in the soil require heat to produce necessary nutrients for the crop, and the solar radiation being the major source of heat that affects the crops, it is therefore advisable for agriculturists to sufficiently increase the moisture content of their garden/farm early in the morning before the sun comes up to increase the thermal conductivity of the soil. As the intensity of the sun increases, the soil will have enough ability to absorb heat necessary for these biological processes. If the wetting is done in the noon, instead of increasing the thermal conductivity of the soil, it will rather cool the temperature down and will cause more harm than good. Moreover, according to the results gotten from the research, at a low wet level or moisture content, the clay-loam soil generates more heat than the sandy-loam as a result of increasing solar radiation and internal heat. However, when the wet level increases, the temperature of the sandy-loam soil rises pass that of clay-loam both in level and at rate. Therefore, in term of required heat, aside some other factors that are necessary for plant growth, when farmers have stable water source for irrigation or wetting of farmland, sandy-loam soil will be a good choice for the plantation. But, in situation when there is no adequate source of water to irrigate or wet the farmland, clay-loam soil will be a better choice. This research work focuses more on soil temperature as an important factor required by the soil in the formation of nutrients for crop germination and growth. Nevertheless, it should be noted that there are other factors that are responsible for the growth of the crops which are not captured in this work. Besides, there are other soil samples that are not considered in this research which can also be incorporated in a future work.

\section{Competing Interests}

The authors declared that they do not have any potential conflict of interest regarding this publication.

\section{How to Cite this Article:}

F. Akinpelu, O. Olaleye, and R. Alabison, "A Comparison of the Effects of Solar Radiation on Sandy-Loam and Clay-Loam Soils with Convective Boundary Condition”, Int. Ann. Sci., vol. 8, no. 1, pp. 130-137, Nov. 2019. doi: 10.21467/ias.8.1.130-137

\section{References}

[1] Ambrollah Gharder, "Clay-Loam Soil Thermal Properties Survey." International Journal of Advanced and Applied Sciences, 1(6): 31 - 36, 2014.

[2] Abu-Hamdeh Nidal H. and Reeder Randall C., "Soil Thermal Conductivity: Effects of Density, Moisture, Salt Concentration and Organic Matter," Soil Science Society of America Journal, 64: 1285 - 1290, 2000. 
[3] Ying Zhao and Bingcheng Si, "Thermal properties of sandy and peat soils under unfrozen and frozen conditions", Soil and Tillage Research, 189: 64 - 72, June 2019.

[4] Sen Lu, Yili Lu, Wei Peng, Zhaoqiang Ju and Tusheng Ren, "A generalized relationship between thermal conductivity and matric suction of soils", Geoderma, 337: 491 - 497, March 2019.

[5] Ian Ofrikhter, Alexander Zaharov, Andrey Ponomaryov and Natalia Likhacheva, "Modeling heat transfer process in soils", MATEC Web of Conferences 251, 02048 (2018).

[6] David Bertermann, Johannes Müller, Simon Freitag and Hans Schwarz, "Comparison between Measured and Calculated Thermal Conductivities within Different Grain Size Classes and Their Related Depth Ranges", Soil Syst. 2018, 2(3), 50.

[7] Peter L.O'Brien, Thomas M.DeSutter, Francis X.M.Casey, EakalakKhan and Abbey F.Wick. "Thermal remediation alters soil properties - a review", Journal of Environmental Management, 206: 826-835, 2018.

[8] Xuezhen Zhang, Zhe Xiong and Qiuhong Tang, "Modeled effects of irrigation on surface climate in the Heihe River Basin, Northwest China", Journal of Geophysical Research: Atmospheres, 122: 7881 - 7895, 2017.

[9] Momen R. Mousa, Mostafa A. Elseifi and Zhongjie Zhang, "Evaluation of Moisture Damage under CrackSealed Asphalt Pavements in Louisiana", Transportation Research Record: Journal of the Transportation Research Board, 2673(3): 460-471, March 2019.

[10] Onwuka Brown Mang, "Effects of soil temperature on some soil properties and plant growth". Advances in Plants \& Agriculture Research , 8 (1): 34-37, 2018.

[11] Oladunjoye M.A. and Sanuade S., "Thermal Diffusivity and Specific Heat of Soils in Olorunsogo Power Plant, Southwestern Nigeria," International Journal of Research and Reviews in Applied Sciences, 13(2): 3502 - 3521, 2012.

[12] Danelichen V.H.M., Biudes N.S., Souza M.C., Machado N.G., Curado L.F.A. and Nogueria J. "Soil Thermal Diffusivity of a Gleyic Solonetz Soil Estimated by Different Methods in the Brazilian Pantanal." Open Journal of Soil Science, 13(3), 15 - 22, 2003.

[13] Monika Rerak, "Selected soil thermal conductivity models." E3S Web of Conferences 13, 02003 (2017).

[14] Usowicz Boguslaw and Usowicz Lukasz, "Thermal conductivity of soils-comparison of experimental results and estimation methods," 2014.

[15] Ross H. McKenzie. "Understanding the Effects of Sunlight, Temperature and Precipitation". Top Crop Manager (2017).

[16] Smriti Chand. "Cultivation of Rice: Suitable Conditions Required for the Cultivation of Rice", (2019).

[17] Kamal Kumar Agrawal, Ghanshyam Das Agrawal, Rohit Misra, Mayank Bhardwaj and Doraj KamalJamuwa, “A review on effect of geometrical, flow and soil properties on the performance of Earth air tunnel heat exchanger", Energy and Buildings, 176: 120 - 138, 2018.

[18] Ahmed A. Abdelhafez, Mohamed H. H. Abbas, Tamer M. S. Attia, Walid El Bably and Samira E.Mahrous, "Mineralization of organic carbon and nitrogen in semiarid soils under organic and inorganic fertilization", Environmental Technology \& Innovation, 9: 243 - 253, 2018.

[19] Mohammed Ibrahim S., "Radiation Effects on Mass Transfer Flow through a Highly Porous Medium with
Heat Generation and Chemical Reaction". IRSN Computational Mathematics, Volume 2013, Article ID 765408.

[20] Nwaigwe C., "Mathematical Modeling of Ground Temperature with Suction Velocity and Radiation". American Journal of Scientific and Industrial Research, 238-241, 2010.

[21] Krishna M. Veera and Reddy M. Gangadhar, "MHD Convective Rotating flow past an oscillating porous plate with Chemical Reaction and Hall Effects". IOP Conf. Series: Materials Science and Engineering (p. 149), 2016.

[22] Kareem R. A. and Salawu S. O., "Variable Viscosity and Thermal Conductivity Effect of Soret and Dufor on Inclined Magnetic Field in non-Darcy Permeable Medium with Dissipation". British Journal of Mathematics and Computer Science, 22 (3): 1-12, 2017.

[23] Akinpelu F. O., Alabison R. M. and Olaleye O. A., "Variations in Ground Temperature in the presence of Radiative Heat Flux and Spatial Dependent soil thermophysical property". International Journal of Statistics and Applied mathematics, 2(1): 57-63, 2017.

[24] Akinbobola Temitope E. and Okoya Samuel S., "The Flow of Second Grade Fluid over a Stretching Sheet with Variable Thermal Conductivity and Viscosity in the Presence of Heat Source/Sink," Journal of the Nigerian Mathematical Society, 34: 331-342, 2015.

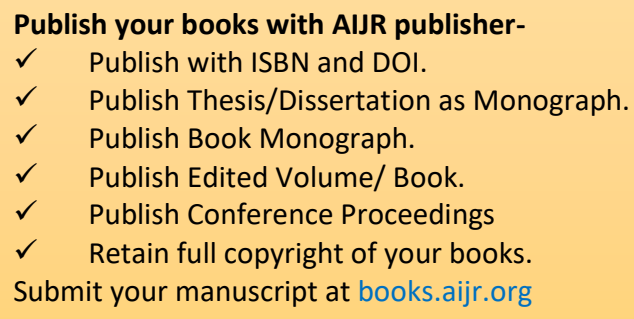

